\title{
Reformas administrativas e o desmonte neoliberal do Estado brasileiro: desafios para o enfrentamento ao novo coronavírus
}

\section{| ${ }^{1}$ Marcia Silveira Ney, ${ }^{2}$ Carlos Alberto Grisólia Gonçalves |}

\author{
${ }^{1}$ Instituto de Medicina Social, Universidade do Estado do Rio de Janeiro. Rio de Janeiro-RJ, Brasil (marcia.ney.unesa@gmail.com). \\ ORCID: 0000-0002-3262-565X \\ ${ }^{2}$ Instituto de Medicina Social, Universidade do Estado do Rio de Janeiro. Rio de Janeiro-RJ, Brasil (carlosalberto.psic@gmail.com). \\ ORCID: 0000-0003-2157-4997 \\ Recebido em: 09/06/2020 \\ Aprovado em: 11/06/2020 \\ Revisado em: 18/06/2020
}

DOI: http://dx.doi.org/10.1590/S0103-73312020300301

Na semana em que este texto foi escrito, o Brasil havia superado a marca dos 30 mil óbitos pelo novo coronavírus - SARS-CoV-2 (BRASIL, 03/06/20). É reconhecido que esse número de mortes é subestimado, já que o país está entre os que menos realizam testes no mundo (OMS apud WORLDOMETERS, 03/06/20). Além disso, os impasses no seio do Governo Federal em relaçáo à estratégia de controle da doença resultaram na exoneração de dois ministros da Saúde em plena pandemia, que somados à escolha pela não testagem em massa e afrouxamento da quarentena fragilizam ainda mais a situaçáo. $O$ país foi atingido pela pior crise sanitária dos últimos cem anos em um contexto político de extrema fragilidade das instituiçóes republicanas e da capacidade estatal para direcionar os esforços na contenção do agravo. Os problemas do Ministério da Saúde, principal autoridade sanitária do país, constituem, entretanto, apenas uma pequena parte aparente da fragilidade do órgão, devida a um longo processo de desmonte do Estado, particularmente na área social.

Este texto analisa os efeitos do processo de desmonte do Estado, com base nas diversas reformas administrativas introduzidas por uma visão liberal ou neoliberal que vêm afetando as áreas sociais como um todo, especialmente na área da saúde. $\mathrm{O}$ período escolhido para o foco da análise é compreendido entre o início do regime 
militar até nossos dias, com ênfase na década de 1990, início da implantação do Sistema Único de Saúde (SUS) e da última abrangente reforma do Estado, promovida pelo governo Fernando Henrique Cardoso (FHC). O fio condutor da argumentação será a desconstrução e fragilização da função pública, com os consequentes efeitos deletérios para a burocracia estatal.

Segundo Florisvaldo Dutra de Araújo, houve, depois de 1930, uma opção clara pelo regime estatutário para os servidores públicos, a partir da publicação do Decretolei no 1.713/1939, que instituiu o Estatuto dos Funcionários Públicos Civis da União (2007, p. 148). Alaim de Almeida Carneiro afirmou a este respeito que: "A fixação do conceito de funcionário público e a repulsa definitiva da tese contratual são os dois elementos nucleares do Estatuto [...]" (CARNEIRO, 1945, p. 332). O governo de Getúlio Vargas chegou a estender de forma obrigatória para o Distrito Federal, estados e municípios a adoção do Estatuto por meio do Decreto-lei no 3.070/1941 (ARAÚJO, 2007, p. 150) — só para funçōes temporárias, como obras, se admitia contratar funcionários em regime diferente do estatutário. Na década de 1950, a aprovação da Lei no 1.890/1953, segundo Araújo, "marcaria o primeiro passo na introdução da legislação trabalhista comum no âmbito da função pública" (2007, p. 154). Após o golpe militar, a situação começou a mudar, em 9 de abril de 1969, com a publicação do Decreto no 64.335, que instituiu a Comissão de Reforma do Pessoal Civil (BRASIL, 1969).

Nesse contexto antidemocrático, deu-se a segunda grande reforma administrativa do século XX no Brasil, trazida pelo Decreto-Lei no 200/1967 (BRASIL, 1967). A descentralização administrativa estabelecida pelo Decreto-Lei deu origem a diversas autarquias, fundações, empresas públicas e de economia mista (BRASIL, 1967, art. $5^{\circ}$ ), e tais instituiçôes podiam contratar servidores pelo regime da Consolidação das Leis do Trabalho - CLT (BRASIL, 1967, Art. 182). A partir de então, no Estado brasileiro, "a marca maior do modelo do crescimento foi mesmo a expansão da administração indireta” e, consequentemente, do regime celetista, em detrimento do regime estatutário (COSTA, 2008, p. 853).

Segundo Marcelo Douglas de Figueiredo Torres, "além de normatizar e padronizar procedimentos nas áreas de pessoal, compras governamentais e execução orçamentária [...]” (2004, p. 153), o decreto estabeleceu os seguintes princípios: 1) planejamento (execução orçamentária e financeira); 2) coordenação dos ministérios; 3) descentralização, através de convênios e concessôes para a administração 
indireta e o setor privado; 4) delegação de competências nas atividades rotineiras e burocráticas, liberando o poder central para formulação, regulação e normatização; e 5) controle. Trouxe, desta forma, importantes medidas de modernização da burocracia estatal brasileira.

A concessão regulamentada pelo DL no 200/1967 para a contratação de servidores pelo regime da CLT foi disseminada, em 1974, pela Lei no ${ }^{\circ}$ 6.185, que segundo Araújo, "representou clara opção pelo regime da legislação trabalhista na função pública federal" (2007, p. 156). Esse autor afirma, ainda, que as "disposiçôes estatutárias" se restringiam às "atividades inerentes ao Estado" que não pudessem ser efetuadas pelo setor privado, como a "[...] Segurança Pública, Diplomacia, Tributação, Arrecadação e Fiscalização de Tributos Federais e contribuições previdenciárias, e no Ministério Público" (ARAÚJO, 2007, p. 156-157). Essas medidas legais fragilizaram o vínculo estatutário dos servidores público e pode-se dizer que fazem parte de um projeto mais abrangente de desmonte gradual da burocracia estatal e do próprio Estado. Essa lei de 1974 trazia a primeira formulação de "funçóes essenciais" do Estado, restringindo às mesmas o regime estatutário, ideia que viria a ser retomada, mais de 20 anos depois, na reforma promovida pelo MARE, em 1995.

O regime militar fortaleceu o papel do setor privado na saúde em diferentes aspectos: criou os seguros privados de saúde pelo Decreto-lei no 73/1966, dando início ao setor de seguros privados de saúde no Brasil (ALMEIDA, 1988, p. 10; BRASIL, 2017); ampliou a participação do setor privado na execução dos serviços e financiou a construção de unidades privadas de serviços de saúde (BRAGA; PAULA, 1986, p. 128). Dentre as açôes que favoreceram o setor privado, o Instituto Nacional de Previdência Social (INPS) criou o Plano de Pronta-Ação (PPA) que recomendava a compra de serviços de saúde ao setor privado. O PPA provocou verdadeiro boom dos gastos com saúde por parte da Previdência Social, principalmente dos gastos com prestação de serviços privados (CORDEIRO, 1984, p. 80; BRAGA; PAULA, 1986, p. 99, 116-118). Dessa forma, o regime militar estimulou o crescimento do setor privado de saúde no país, como decorrência as unidades com fins lucrativos passaram de 14,4\% do total em 1960, para 45,2\% em 1975 (BRAGA; PAULA, 1986, p. 110).

A crise da dívida externa iniciada em 1980 criou as condiçôes que impuseram o ajuste estrutural de cunho neoliberal, exigido pelo Banco Mundial e pelo Fundo Monetário Internacional e a adoção plena do receituário neoliberal a partir dos anos 1990 (FIORI, 2001; TORRES, 2004). O ajuste estrutural criou, dessa forma, o 
ambiente para uma terceira reforma administrativa nos anos 1990. As duas anteriores ocorreram em períodos autoritários - durante o Estado Novo e o regime militar iniciado em 1964 - a nova reforma se daria num ambiente de constrangimento externo causado pela crise da dívida externa.

O contexto político da redemocratização se deu em meio a disputas de forças francamente contraditórias. O impulso pela redemocratização não foi suficiente para superar o aparato repressivo do período militar, protegido pelo dispositivo da anistia política. As conquistas sociais da "Constituição cidadã", conviveram com a presença de um forte setor privado, garantindo que os interesses de mercado fossem mantidos tanto na Educação, quanto na Saúde. Um bloco multipartidário, conhecido ainda hoje por "Centrão", de cunho claramente conservador, atuou para frear o ímpeto reformista tanto no que diz respeito ao aprofundamento da democracia, quanto da política social (SALLUM JR., 1994). A criação de subsídios públicos para o setor privado na saúde promoveu, e ainda promove, uma transferência direta de recursos que minam as políticas de Estado e ajudaram a formar um dos setores privados de saúde mais ricos do mundo (RODRIGUES; SANTOS, 2017).

A Constituição Federal (CF) de 1988 promoveu um forte movimento de reorganização federativa, fortalecendo a descentralização administrativa e financeira de parte das funçôes de Estado para os municípios e estados, inclusive da saúde. A descentralização prevista na CF 88 introduziu um quadro controverso mediante as particularidades históricas e geográficas da constituição do Estado brasileiro, estabelecendo, segundo Abrucio, uma espécie de: "Federalismo compartimentalizado, em que há mais uma atuação "autarquizada" dos níveis de governo do que o estabelecimento de laços entre eles" (2010, p. 57). A descentralização interferiu na organização do SUS, criado pela Constituição, fortalecendo de forma um tanto desmensurada o papel dos municípios, o que vem dificultando, até hoje, a organização de redes de saúde regionalizadas (KUSHNIR; CHORNY, 2010).

Nas primeiras eleiçóes diretas após o fim do regime militar, elegeu-se o candidato de inclinação neoliberal Fernando Collor de Mello (1990-1992), que defendia a diminuição do Estado e o "combate aos marajás", forma de atacar o que considerava como um "inchaço" da máquina pública e os "privilégios" do funcionalismo. Seu governo era alinhado com o Consenso de Washington, que defendia "[...] abertura comercial, superávit fiscal, privatização de empresas estatais, enxugamento das máquinas públicas e desregulamentação" (TORRES, 2004, p. 168). Esse receituário 
prejudicava a implantação das políticas sociais universais da CF de 1988 e não era favorável à existência de uma burocracia pública de carreira. Surgiram, desde então, diversas medidas legais que minaram o quadro de servidores estatutários, em médio e longo prazos, sucessivos ajustes fiscais foram estrangulando os recursos orçamentários para os recursos humanos, deteriorando suas condiçóes de trabalho, reduzindo seus vencimentos e benefícios sociais, além de não repor as vagas deixadas pelas aposentadorias.

O governo de Fernando Henrique Cardoso (1995-2003), embalado pela alta popularidade da estabilização da inflação alcançada pelo Plano Real, conseguiu apoio político para realizar uma reforma administrativa que viria anular a decisão constitucional de criação do Regime Jurídico Único (RJU), que prometia valorizar os servidores estatutários. Para tanto, criou o Ministério da Administração Federal e Reforma do Estado (MARE), sendo chefiado pelo ministro Luiz Carlos BresserPereira, o qual se pautou pela diretriz da nova gestão pública e apresentou o Plano Diretor da Reforma do Aparelho do Estado em 1995.

No campo legal, as principais mudanças para o funcionalismo decorreram das Emendas Constitucionais (EC) no. 19 e 20 de 1998, as quais versavam sobre o teto de gastos com pessoal, alteraçóes no RJU, além de pretensos: aumento do controle social sobre os gastos públicos; e o princípio da eficiência na administração pública. Estas medidas se basearam no modelo gerencial, ou administração voltada para os resultados, e estabeleceram três instituiçôes administrativas base, as agências reguladoras, as agências executivas e as Organizações Sociais (OS). A criação das OS e Organizaçôes da Sociedade Civil e de Interesse Público (OSCIPS) visavam transferir a execução das políticas sociais para o setor privado (BRASIL, 1998).

A EC no. 19/1998 constituiu um divisor de águas no campo dos recursos humanos, por conta da redefinição de uma hierarquia nas funções estatais e, desta forma, do próprio papel do Estado. Os artigos 20 e 21 vedavam, respectivamente, os repasses entre esferas em amparo as contas públicas no tocante à remuneração com pessoal e abrem o precedente para Lei de Responsabilidade Fiscal (LRF) na limitação de gastos em função do orçamento público (BRASIL, 1998, 2000). As disposiçôes da Lei Complementar no. 101/2000 se impuseram para toda a administração pública, nas três esferas de governo. Seu artigo 19 limitou os gastos com recursos humanos ao equivalente a $50 \%$ da receita líquida da União e $60 \%$ dos estados e municípios (BRASIL, 2000). 
Essa determinação foi apresentada como uma limitação virtuosa dos gastos públicos, vinculando as despesas a contrapartidas de receitas, mas logo veio a se mostrar como uma limitação rígida aos gastos com pessoal, que atingiu duramente políticas sociais como educação e saúde, que são intensivas em recursos humanos. A LRF estimulou a entrada das OS e Oscips e outras formas de terceirização na prestação de serviços públicos, especialmente na saúde. Passou-se, desta forma, a repassar ao setor privado recursos públicos que não podiam ser gastos com recursos humanos próprios, a Lei foi mais um instrumento de privatização no setor de saúde.

O plano diretor previu uma diferenciação das funçôes "essenciais" de Estados e aquelas que seriam executadas por instituições da administração indireta. A reforma Bresser-Pereira definiu as carreiras e funçóes estratégicas, ou essenciais, do Estado, reduzidas na diplomacia, nas finanças públicas, na área jurídica e nas carreiras de gestão - tal qual foram elencadas na Lei no 6.185/1974. Às carreiras essenciais caberia a profissionalização e a valorização; aos demais, incluídos os serviços de maior influência às populaçôes vulneráveis, competiria a lógica de mercado (TORRES, 2004). Ademais, houve a desestatização de atividades econômicas fundamentais.

A restrição de investimento na carreira pública relegou às demais áreas um papel secundário, suscetível às peculiaridades políticas regionais, além da falta de investimento e de progressão na carreira - o que se contrapóe à motivação necessária para o trabalhador que executa a política social/pública na ponta, em contato direto com o cidadão. Cabe questionar como, no federalismo de um país continental, com aproximadamente 5.570 municípios, com profundas disparidades demográficas e econômicas, poderá se efetivar as políticas de Estado com uma definição tão restrita do "essencial".

Segundo Abrucio (2007), um dos equívocos da reforma Bresser foi a contraposição do modelo burocrático weberiano aos princípios da nova gestão pública, como se o primeiro fosse uma etapa a se superar em função do segundo. Nesta mesma direção, Diniz (2001) aponta que a oposição formalista às velhas estruturas de poder da sociedade brasileira encontrou mais um continuum do que um opositor. A autora afirma que nunca tivemos uma administração burocrática de fato, e que os princípios meritocráticos universalistas da reforma introduzida por Getúlio Vargas na década de 1930 coexistiram, insuladas, com as práticas clientelistas tradicionais das elites regionais. As reformas da década de 1990 tinham o claro objetivo de descontruir a estrutura administrativa da era Vargas, os projetos 
desenvolvimentistas dessa época e do governo militar, marcando uma direção não intervencionista do Estado dali em diante.

O desmonte do Estado brasileiro é um longo processo que remonta à constituição de sua burocracia pública. A máquina administrativa atual é o resultado da disputa de forças internas e externas, representadas na concorrência entre projetos de desenvolvimento nacional e oligarquias regionais, assim como na agenda de austeridade prescrita por organismos financeiros mundiais. $\mathrm{O}$ momento atual revela a necessidade do fortalecimento das políticas de Estado e reavaliação da suposta eficácia das leis do mercado.

O desmonte do Estado que vem ocorrendo ao longo dos anos implica descontinuidade de açóes e da manutenção de quadros de servidores públicos de carreira nos equipamentos de saúde. A capacidade de resposta do SUS na atual pandemia é um exemplo desse processo, mas não se resume a ele. Ainda assim, o sistema de saúde público resiste e reafirma seu mandato social na oferta dos serviços "essenciais" para a população. É o que tem se mostrado pelo trabalho de seus servidores, os quais resistem em prol da política de saúde, assumindo um alto risco de suas vidas e na contracorrente dos sucessivos posicionamentos políticos do governo federal.

\section{Referências}

ABRUCIO, L. F.; PEDROTI, P.; PÓ, M. V. A formação da burocracia brasileira: a trajetória e o significado das reformas administrativas. In LOUREIRO M. R. et al. (Orgs.). Burocracia e politica no Brasil. Desafios para a ordem democrática no século XXI. Rio de Janeiro: Ed FGV, 2010.

ABRUCIO, L. F. Trajetória recente da gestão pública brasileira: um balanço crítico e a renovação da agenda de reformas. Rev. Adm. Pública, Rio de Janeiro, v. 41, n. esp., p. 67-86, 2007.

ALMEIDA, C. O mercado privado de serviços de saúde no Brasil: panorama atual e tendências da assistência médica suplementar (IPEA, Texto para discussão n. 599, nov. 1988). Brasília: IPEA, 1988, 49p.

ARAÚJO, F. D. Os Regimes Jurídicos dos Servidores Públicos no Brasil e suas vicissitudes históricas. Revista da Faculdade de Direito da UFMG. Belo Horizonte, v. 50, p. 143-169, janjul, 2007.

BRAGA, J. C. S.; PAULA, S. G. Saúde e previdência, estudos de política social. São Paulo: Hucitec, 1986, 224p. 
BRASIL. Presidência da República. Decreto-Lei no 200, de 25 de fevereiro de 1967. Dispóe sobre a organização da Administração Federal, estabelece diretrizes para a Reforma Administrativa e dá outras providências. Diário Oficial da União, Brasília, 27 fev. 1967.

. Decreto no 64.335, de 9 de abril de 1969. Dispóe sobre a elaboração de Plano de Classificação de Cargos e de Nôvo Estatuto do Servidor Federal cria a Comissão de Reforma Administrativa do Pessoal Civil determina a reorganização do DASP e dá outras providências. Diário Oficial da União, Brasília, 10 abr. 1969.

. Congresso Nacional. Lei Complementar no 101, de 4 de maio de 2000. Estabelece normas de finanças públicas voltadas para a responsabilidade na gestão fiscal e dá outras providências. Diário Oficial da União, Brasília, 5 maio 2000.

. Ministério da Saúde. Painel Coronavírus. Disponível em: https://covid.saude.gov.br/; Acesso em: 03 de jun. 2020.

BRESSER-PEREIRA, L. C. A reforma gerencial do estado de 1995. Revista de Administração Pública. Rio de Janeiro, jul/ago. 2000.

CARNEIRO, A. de A. O Estatuto dos Funcionários e a Legislação Posterior. Revista de Direito Administrativo. Rio de Janeiro-Sáo Paulo, n. 1, p. 330-336, jan. 1945.

CORDEIRO, H. A. As empresas médicas: as transformações capitalistas da prática médica. Rio de Janeiro: Graal, 1984, 175p.

DINIZ, E. Globalização, reforma do estado e teoria democrática contemporânea. São Paulo Perspectivas. São Paulo, v. 15, n. 4, p. 13-22, dez. 2001.

FIORI, J. L. 60 liçôes dos 90, uma década de neoliberalismo. Rio de Janeiro: Record, 2001, 236p.

COSTA, F. L. Brasil: 200 Anos de Estado; 200 Anos de Administração Pública. Revista de Administração Pública. Rio de Janeiro, v. 42, n. 5, p. 829-74, set/out. 2008.

KUSCHNIR, R.; CHORNY, A. H. Redes de atençấo à saúde: contextualizando o debate. Ciência \& Saúde Coletiva. Rio de Janeiro, v. 15, n. 5, p. 2307-2316, 2010.

RODRIGUES, P. H. A.; SANTOS, I. S. Os novos riscos sociais não são só europeus, também chegaram ao Brasil e exigem respostas das nossas políticas sociais. In: . (Orgs.). Políticas e riscos sociais no Brasil e na Europa: convergências e divergências. Rio de Janeiro: Cebes; São Paulo: Hucitec, 2017.

SALLUM JR, B. Transição política e crise do Estado. Lua Nova. Rio de Janeiro, v. 32, p. 133167, 1994.

TORRES, N. D. de F. Estado, democracia e administração pública no Brasil. Rio de Janeiro: Editora FGV, 2004. 